\title{
Research on the present situation of coordinated development and the innovation path of Beijing-Tianjin-Hebei industry
}

\author{
Qingmin Yuan ${ }^{1, a}$ and Ai-zhen Zhang ${ }^{2, b}$ \\ ${ }^{1}$ School of Management of Tianjin technology University, Tianjin 300384, China; \\ ${ }^{2}$ School of Management of Tianjin technology University, Tianjin 300384, China. \\ a980798984@qq.com, ${ }^{\text {b}} 642013305 @ q q . c o m$
}

Keywords: Beijing-Tianjin-Hebei, industrial collaborative innovation, innovation path.

\begin{abstract}
Regional economic integration is the trend of the development of the market economy, as one of the most active economic region in China even all over the world, and Beijing-Tianjin-Hebei region has great development potential. Giving full play to the industrial advantage, realizing the coordinated development of three industries, and achieving the Beijing-Tianjin-Hebei industry together, is of great significance to promote regional economic development of the Beijing-Tianjin-Hebei region. And the basic power of coordinated development lies in the innovation drive, collaborative innovation especially industrial cooperative innovation is the core of the innovation drive. Beijing-Tianjin-Hebei are analyzed in this paper, the necessity of the coordinated development of regional industry, expounds the three coordinated development restriction factor, proposed the Beijing-Tianjin-Hebei regional industry innovation and development of the implementation of the path together.
\end{abstract}

\section{Introduction}

Beijing-Tianjin-Hebei region is the most developed economic zone in the north of China and the largest industrial base, the regional economic development in China in the 21st century new luminescent spot, the national economic development of the new leader, which has a good geographical position, good economic foundation, strong technology power aspects of advantages. But compared with the pearl river delta and Yangtze river delta, Beijing-Tianjin-Hebei industry efficiency gap is big, from hebei, and industrial efficiency level of hebei is low, although associated with historical administrative divisions, but the main reason lies in the Beijing-Tianjin-Hebei industry innovation ability is insufficient, lack of consensus of the positioning system of the three regions, subject to their respective market boundaries of the Beijing-Tianjin-Hebei region and the interests of the public service boundary circulating accumulation.

In the development of Beijing-Tianjin-Hebei region economy,therefore, give full play to the industrial advantage, strengthen cooperation, realize the effective docking and transfer of three industries, which has important strategic significance to promote the coordinated development of their regional industry. In 2014, the coordinated development of Beijing-Tianjin-Hebei is rising as national strategy, the coordinated development of Beijing-Tianjin-Hebei strategic prelude to officially opened. To promote the coordinated development of industry of Beijing-Tianjin-Hebei, it must be clear of Beijing-Tianjin-Hebei overall orientation, function orientation and industry position and the orientation of industrial spatial layout and the management pattern, establish market and decided by the Beijing and Tianjin core industry characteristics of Beijing-Tianjin-Hebei industry coordinated development of the single market, build the investment and financing platform and the public service platform of the Beijing-Tianjin-Hebei region, promote Beijing-Tianjin-Hebei industry innovation comprehensively.

\section{Problems of Beijing-Tianjin-Hebei industry collaboration}

When talking about the existing problems in the development of Beijing-Tianjin-Hebei synergy, some think that development level disparity is great, some think it is fragmented and so on. From the 
perspective of the phenomenon of problem, the development gap, less contact between before and after the regional industry and the industrial structure identical, vicious competition, environmental pollution, ecological destruction and so on can be seen as industrial synergy that exist in the phenomenon, this paper analysis the causes of these phenomena and mechanism, mainly including the followings:

(1) a single value orientation of regional development cause damage to the interests of the whole area. A lot of local government work basically has two, one is stability, the second is to develop the economy. Too much emphasis on economic development, regional development problems, the most prominent example is the relationship between ecology and economy. The cause of regional coordination problem above is a place where only economic development considerations, national main body function regionalization has been compiled, but the problem is not solved, mechanism system even ecological headwater could consider developing "polluting" economy. To consider environment, excess production capacity is insufficient, it is also a regional industry development caused by the value orientation of the single.

(2) an insufficient market dynamics coordinated development lack of self-organizing ability. Beijing-Tianjin-Hebei region relatively high proportion of heavy industry, after the reform and development, industry economic development are not from the market economy step by step, so the market mechanism development has a great gap compared with the Yangtze river delta region. Again, because supply group is large and enterprise scale is small, the government is difficult to influence the business decisions.

(3) the industry transfer lacked the ability to undertake and mechanism guarantee. Currently affected by governments, the collaborative development of the three regions are constrained, in other words, the development of three are lack of incremental benefit sharing mechanism, especially on the issue of strategic emerging industry development, the competition is fierce, many non-market factors hinder the industrial spatial layout optimization.

\section{The necessity of industry collaborative innovation for Beijing-Tianjin-Hebei}

Industry coordinated development theory is that any system in the interaction between subsystems determines the overall behavior of the system, thus forming a synergistic effect. Some form of structure combination, namely between subsystems through exerting the subsystem sum cannot reach the effect. Technological progress brings highly fine division of labor, the industry itself is a complex network of labor division, industry synergy is to promote the industrial division of labor. It is generally considered that industry synergy is to point to by factors such as technology, economy, environment, society, resources, industry or industry group coordination and cooperation between each other to form an orderly structure, the process of the latter's is more than one industry and its related industry in the development process of mutual cooperation, mutual coordination and division of labor in the increasingly complex network to solve the problem well coordinated development of industry. And the collaborative relationships often through industrial input-output relation to maintain the product or service, is a kind of longitudinal association between upstream and downstream.

Achieving industrial collaborative innovation is the basic way to realize Beijing-Tianjin-Hebei industry collaboration, mainly from the following three ways:

(1)Around the world, collaborative innovation has become a new organization mode to improve regional core competitiveness. The research report of US Council on Competitiveness in 2004 in the USA innovation pointed out that with the progress of science and technology, enhanced technical complexity, the speeding up of global economic integration, there are a series of new changes in innovation, once the relations between each other before that are considered antagonistic,is now increasingly evolved into complementary even symbiotic relationship, therefore a new relationship need to be established between "enterprises, governments, educators and workers, which can form a innovation ecosystem in the 21st century".

(2)Look at the domestic, collaborative innovation has become a new innovation model to transform the pattern of economic development. After decades of rapid economic development in our country, a series of structural problems highlighted increasingly, unbalanced economic structure, 
external market space compression, decrease environmental carrying capacity of resources, population, land disappearing dividend element such as "modernity", the economic crisis continues to spread, low carbon war pressure and so on is a huge pressure to make the sustainable development of economy of our country. At the same time, the "made in China" industry development mode, make many industry in China in the international division of production value chain low-end, industry international competitiveness is not essential. Transformation of the mode of economic development and implement the development strategy of innovation, is the key to build an innovative country. Therefore, the report suggests that the party's 18 plots with a global perspective and promote innovation, to pay more attention to the collaborative innovation.

(3) Focus on the Beijing-Tianjin-Hebe, collaborative innovation is the inevitable choice to crack area development bottleneck and build the world-class innovation center. Beijing-Tianjin-Hebe region innovation resources in China's most densely populated, one of the most abundant area industrial base, is the third growth pole, driving the development of our country's economy is shouldering the world-class technology and industry innovation center, lead our country to participate in a new round of industrial revolution and the great historical mission of science and technology competition. However, Beijing-Tianjin-Hebei region ,as a regional economic entity,compared with the rest of the world famous economic zone and the Yangtze river delta and pearl river delta region, there is a big gap in industry level, its development is also facing many problems.

\section{Four Suggestions to Beijing-Tianjin-Hebei industry collaboration}

In order to realize the coordinated development of Beijing-Tianjin-Hebei industry much better, this paper argues that it should focus on the following six aspects:

First, we should control and protect the environment strictly, increase the adjustment of industrial structure, improve the ecological compensation mechanism. We should strictly control and protect the environment in the future, such as steel, cement, glass industry development should be positive transformation, to energy conservation and environmental protection, to let go of the government hand, let the market to adjust production capacity; the modification of inefficient coal-fired boilers should be "unit energy consumption, water consumption index" to "total energy consumption, water consumption index", should step up rivers and lakes water resources comprehensive management, should establish the long-term ecological compensation mechanism, within the scope of Beijing-Tianjin-Hebei guide rational population distribution.

Second, we should establish the incremental benefit distribution mechanism, arouse the enthusiasm of developed region to drive the coma. There are many ways to achieve incremental deployment at present, one is dominated by the government of the enclave economy pattern; second is condominium with place, in the form of industrial park development more economy.

Third, intensify regional industry pilot demonstration, the establishment of regional innovation system and industry collaboration system, accelerate the emerging industries.

Fourth, establish industrial innovation to guide fund joint venture, set up industrial innovation to guide fund, and set up a innovation fund management committee. Innovation fund mainly in high-end manufacturing, new materials, new energy, aerospace, a new generation of information technology and other strategic emerging industries, funding including Beijing-Tianjin-Hebei three universities, research institutions, science and technology enterprises, etc., we need to promote regional industry innovation and power.

Fifth, on the basis of preparation for the industry's overall development plan, prepare industrial collaborative innovation roadmap and action plan. Led by the government, the three ministry department, administrative department of science and technology, industrial park, the organization department together with the relevant industry experts, soft science research institutions to constantly approached, deepening research discussion, according to the three innovation elements distribution, important node external radiation condition, different industries and regional innovation demand situation, the innovation synergy between regional industry situation, determine the industry in the early period of the collaborative innovation action plan and follow-up promotion project. 
Sixth, build the regional industry collaborative innovation platform. Zhongguancun collaborative innovation platform for reference model, by the government organizations, enterprises, universities, research institutions, finance, service mediation and other structures, Beijing-Tianjin-Hebei industry collaborative innovation platform. Platform is the transformation of scientific and technological research and development and industry of one-stop service platform, its organizational structure can include innovation policy first try working group, the industrial planning and construction team, the new technology and new products of government procurement and application promotion team, major science and technology projects and major scientific and technological achievement industrialization project approver group.

\section{Conclusion}

The Beijing-Tianjin-Hebei industry coordinated development of regional development value orientation of the single, weak market dynamics, hebei continues the poor transfer ability of trouble. Many security measures in the future, should pay special attention to three increment benefit sharing mechanism of the Beijing-Tianjin-Hebei region, environmental protection and governance, and emerging industries, etc. The implementation of planning in the future, to the coordinated development level objective measurement. To enterprises, the use of virtual production model, such as increasing of Beijing-Tianjin-Hebei tripartite division of labor and cooperation, avoid vicious competition. To achieve industry, science and technology, market, the innovation of the personnel, finance and other aspects of management mode, according to the industrial development and changes and specific requirements of different regional innovation policies to guide and support. According to the industrial development foundation and features of the three regions, based on innovation ecosystem formation process and three industry development needs, and Beijing-Tianjin-Hebei places should according to "better, groups, group chain, netting system" collaborative innovation path, finally formed by the research, development, application innovation ecological system consisting of three communities.

\section{Reference}

[1]. Sun Hu, Qiao Biao. Problems and Suggestions of the Beijing-Tianjin-Hebei industry coordinated development [J]. China soft science, 2015, 28 (7) : 68-74.

[2]. Tracy, KouJing. The coordinated development of Beijing-Tianjin-Hebei industry analysis [J]. Journal of new horizons, 2015,1.104-109.

[3]. Yang Jie, Wang Yan, Liu Xiao. The coordinated development of Beijing-Tianjin-Hebei regional industry path analysis [J]. Value engineering,2009,4.35 -37.

[4]. Jiuwen Sun, Hong-mei Zhang. Integration of the Beijing-Tianjin-Hebei region of the coordinated development of industry research [J]. Journal of Hebei university of technology, 2014 (9). 1-7.

[5]. K Laursen, T Reichstein, A Salter.Exploring the effect of geographical proximity and university quality on university - industry collaboration in the United Kingdom [J].Regional studies,2011.

[6].J Bruneel, P d'Este, A Salter.Investigating the factors that diminish the barriers to university industry collaboration[J].Research Policy,2010. 